\title{
Barreiras de acessibilidade urbana: cotidiano das famílias de crianças com deficiências neurológicas
}

\section{Urban accessibility barriers: daily life of families of children with neurological disabilities}

\section{Barreras de accesibilidad urbana: vida cotidiana de las familias de niños con discapacidades neurológicas}

Recebido: 01/05/2020

Aprovado: $20 / 07 / 2020$

Publicado: $22 / 07 / 2020$

\section{Gisélia Gonçalves de Castro ${ }^{1}$ Adriana Santos Camargos ${ }^{2}$ Marilurdes Silva Farias ${ }^{3}$}

Este estudo tem como objetivo compreender as barreiras de acessibilidades a partir da visão das mães de crianças com deficiências neurológicas. Trata-se de uma pesquisa transversal, qualitativa, realizada com 20 mães de crianças em acompanhamento em ambulatório de um município mineiro de fevereiro a setembro de 2019. Constatou-se que 15 delas pertenciam à faixa etária de 31 a 45 anos e 12 eram casadas. Em relação às crianças, 70\% eram do sexo masculino, e 95\% tinham 17 meses ou mais. De acordo com a topografia, houve predomínio da quadriplegia, somando 95\% das crianças. Duas categorias foram construídas a partir das falas das mães: "Barreiras nos Transportes" e, "Barreiras Urbanísticas", apontando assim, descaso com as adaptações para deficientes, principalmente no que diz respeito ao funcionamento dos dispositivos urbanísticos e transporte coletivo. As barreiras de acessibilidade não apenas dificultam a locomoção, mas também prejudicam a inclusão e aumentam a demanda e preocupação dos familiares.

Descritores: Acessibilidade Arquitetônica; Família; Crianças com Deficiências.

This study aims to understand accessibility barriers from the perspective of mothers of children with neurological disabilities. This is a cross-sectional, qualitative study carried out with 20 mothers of children being cared for in an outpatient clinic in a city in the state of Minas Gerais from February to September of 2019. Of those mothers, 15 were between 31 to 45 years of age and 12 were married. Regarding children, 70\% were male, and 95\% were 17 months or older. According to the topography, there was a predominance of quadriplegia, representing $95 \%$ of children. Two categories were elaborated based on the mothers' statements: "Transportation Barriers" and "Urban Barriers", thus pointing out disregard for adaptations for the disabled, especially with regard to the functioning of urban devices and public transportation. Accessibility barriers not only hamper mobility, but also hamper inclusion and increase the demand and concern of family members.

Descriptors: Architectural Accessibility; Family; Disabled Children.

Este estudio tiene como objetivo comprender las barreras de accesibilidad desde la perspectiva de las madres de niños con discapacidades neurológicas. Se trata de una encuesta transversal y cualitativa, realizada con 20 madres de niños en régimen de atención ambulatoria en una ciudad de Minas Gerais de febrero a septiembre de 2019. Se descubrió que 15 de ellas pertenecían al grupo de edad de 31 a 45 años y 12 eran casadas. En relación con los niños, el 70\% eran hombres y el 95\% tenían 17 meses o más. Según la topografía, predominaba la cuadriplejía en el 95\% de los niños. A partir de los discursos de las madres se construyeron dos categorías: "Barreras de Transportes" y "Barreras Urbanísticas", señalando así el descuido en las adaptaciones para los discapacitados, principalmente en lo que se refiere al funcionamiento de los dispositivos urbanísticos y de transporte público. Las barreras de accesibilidad no sólo dificultan la locomoción, sino que también perjudican la inclusión y aumentan la demanda y la preocupación de los familiares.

Descriptores: Accesibilidad Arquitectónica; Familia; Niños con Discapacidad.

1. Fisioterapeuta. Especialista em Saúde Pública. Mestre, Doutora e Pós Doutora em Promoção de Saúde. Docente do Centro Universitário do Cerrado Patrocínio (UNICERP), Patrocínio, MG, Brasil, ORCID: 0000-0003-1132-5647 E-mail: giseliacastro@unicerp.edu.br

2. Fisioterapeuta. Patrocínio, MG, Brasil. ORCID: 0000-0001-5993-2329 E-mail: didicaptc@hotmail.com

3. Enfermeira. Mestre em Ciências da Saúde. Doutora em Ciências. Docente da Faculdade São Luís de Jaboticabal, SP, Brasil. ORCID: 0000-0002-3827-2568 E-mail: malufariasbr@yahoo.com.br 


\section{INTRODUÇÃO}

$\mathbf{0}$

ambiente exerce uma forte influência no crescimento e desenvolvimento da criança, uma vez que é por meio dele que ocorre o desenvolvimento das habilidades, capacidades e aprendizagem infantil. Sendo assim, as crianças, principalmente aquelas com deficiência, devem crescer em um ambiente rico em estímulos motores e sensoriais, oferecendo-lhes informações sobre o meio ambiente e o próprio corpo ${ }^{1}$.

A criança que nasce com alguma deficiência ou adulto incapacitado por um acidente são mais limitados pela sociedade do que pela própria deficiência ${ }^{2}$. Uma das principais causas da exclusão social dos deficientes é a disponibilidade precária de acessibilidade aos meios públicos das cidades, que acabam reduzindo a mobilidade e habilidade do indivíduo fazendo com que este prefira o isolamento ${ }^{3}$.

A acessibilidade ao meio pode ser entendida como a possibilidade que o indivíduo possui de utilizar, de forma segura e autônoma, edifícios, mobiliário, espaços e equipamentos urbanos. Deve-se ter em mente que a acessibilidade não possui foco específico apenas naqueles que possuem algum tipo de deficiência, ao contrário disto; ela visa atender todos os usuários do serviço ${ }^{4}$. Em vista disso, a Associação Brasileira de Normas Técnicas (ABNT) implementou, por intermédio da NBR 9050/2004, padrões e especificações técnicas que devem ser consideradas na fase de elaboração de projetos de construções e instalações e também na adaptação de edificações, mobiliários, espaços e equipamentos urbanos, a fim de deixá-los mais acessíveis ${ }^{5}$.

As construções e projetos de espaços públicos devem ser concebidos, adaptados e executados de forma a serem acessíveis para pessoas portadoras de deficiência ou com mobilidade reduzida 5 . No entanto, mesmo a lei assegurando o direito de acessibilidade e de mobilidade aos necessitados, o que se percebe, muitas vezes, é que os municípios não têm atendido aos parâmetros estabelecidos pela NBR9050/2004. Não é incomum encontrar, por exemplo, construções que não apresentam ao menos uma rota acessível nos ambientes, equipamentos e mobiliário adaptados para pessoas com deficiência ou mobilidade reduzida ${ }^{6}$.

A Lei n. 10.098 , de 19 de dezembro de 2000, estabelece normas gerais e critérios básicos para a promoção da acessibilidade das pessoas portadoras de deficiência ou com mobilidade reduzida. De acordo com essa lei, as barreiras são obstáculos e impedem ou limitam a participação social do indivíduo, a circulação com segurança, o acesso à informação, à compreensão e a liberdade de movimento. Essas barreiras podem ser divididas em: barreiras urbanísticas, arquitetônicas, nos transportes e nas comunicações e na informação ${ }^{7}$.

As mães cuidadoras de crianças com deficiências enfrentam diferentes obstáculos no dia a dia, para proporcionar qualidade de vida aos filhos e também para manter a rotina de cuidados ${ }^{8}$.

A importância da investigação reside no fato de o número de crianças com algum tipo de deficiência cresce cada vez mais e nota-se que, frequentemente, as normas de acessibilidade não são respeitadas. Além disso, a partir dessas informações é possível fornecer subsídios para que se possa, em algum momento, avaliar estratégias e programar ações para a resolução dos principais problemas encontrados.

Assim, este estudo tem como objetivo compreender as barreiras de acessibilidades a partir da visão das mães de crianças com deficiências neurológicas.

\section{MÉTODO}

Trata-se de uma pesquisa de corte transversal com abordagem qualitativa realizada de fevereiro a setembro de 2019, e aprovada pelo Comitê de Ética em Pesquisa, sob o número CAAE 62623416.9.0000.5495. 0 estudo foi realizado em um ambulatório no interior de um município mineiro.

Este estudo se direcionou a mães de crianças com deficiências neurológicas acompanhadas em ambulatório especializado. Após identificação das crianças em prontuários, 
as mães foram convidadas a participar da pesquisa. Nos prontuários se coletou também as seguintes informações: sexo, idade gestacional ao nascer, tipo de parto, idade atual, topografia, bem como alguns dados das mães. Posteriormente, foi realizado o agendamento de acordo com a disponibilidade de cada mãe participante para a realização da entrevista.

Nos dias e horários agendados, foi lido o Termo de Consentimento Livre e Esclarecido. Para garantia de sigilo, as mães foram identificadas pela letra M seguida de números (M1, M2, M3...). Na entrevista com as mães, realizou-se a seguinte pergunta: "Como você percebe a questão da acessibilidade para seu filho?". Para a gravação dos relatos das mães foi utilizado um gravador digital, marca Sony, modelo ICD-PX440.

Para análise da caracterização do perfil de crianças e de suas genitoras, foram utilizados média e desvio padrão. Os dados foram compilados no Epi Info e tabulados no Excel e analisados no programa Statistical Package for Social Sciences (SPSS) versão 18.0 for Windows.

Também foi feita a análise descritiva do cruzamento entre as variáveis análise dos dados qualitativos baseada na Análise de Conteúdo de Minayo ${ }^{9}$ e Gomes ${ }^{10}$, em que a coleta e a análise dos dados ocorreram simultaneamente, realizando a codificação aberta e sua categorização. A codificação aberta é a parte da análise que diz respeito a nomear e classificar o fenômeno por meio de exame exaustivo dos dados.

Durante a codificação aberta, os dados são "quebrados" em pequenas frases, examinados, comparados por similaridades e diferenças. Por intermédio desse processo, o conteúdo é explorado, permitindo novas descobertas. Os dados codificados são agrupados por similaridade. 0 processo de agrupar conceitos relativos ao mesmo fenômeno é chamado de categorização. Cada categoria é considerada saturada, quando não for possível acrescentar novos dados. Após essa etapa, foram realizadas leituras dos resultados obtidos, de modo a apreender as particularidades e determinar a discussão com a literatura da área.

\section{RESULTADOS}

Participaram 20 mães, das quais 15 estavam na faixa etária de 31 a 45 anos, 11 eram casadas, 12 com ocupação do lar e não tinham renda e oito trabalhavam com atividade remunerada.

Caracterizando as crianças, predominou o sexo masculino (70\%), no qual $60 \%$ foi gestada a termo, 85\% nascidos de parto cesáreo e em hospital público. Em relação a idade dos participantes, a maioria das crianças (95\%) estava na faixa etária de 17 meses ou mais e 1 de 0 a 17 meses. De acordo com a topografia, 19 foram classificadas com lesão piramidal, predominando a quadriplegia, sendo apenas 1 extrapiramidal, classificada como Atetose.

Nos dados qualitativos formou-se duas categorias: "Barreiras nos Transportes" e, "Barreiras Urbanísticas".

\section{Barreiras nos Transportes}

No que diz respeito ao transporte coletivo, as mães informaram que esses são adaptados para atender as pessoas com deficiência, porém queixaram-se das falhas no seu funcionamento, pois, muitas vezes, a própria população danifica os acessórios, como o cinto de segurança, por exemplo. Tais queixas podem ser verificadas a seguir:

As rampas dos coletivos nem sempre tão funcionando, né? E outra eles não esperam a gente colocar o cinto, né?... você sobe a cadeira no coletivo... a gente tá colocando o cinto e o coletivo tá andando... é o maior desespero... [M20]

Os próprios passageiros estragam aquele lugar onde é da criança ficar... eu nunca andei num coletivo que tivesse o cinto de passar no meu filho na cadeirinha... e as rampas dos coletivos nem sempre tão funcionando. [M13]

\section{Barreiras Urbanísticas}

Sobre as vagas para cadeirantes nos estacionamentos, as mães relataram que são insuficientes e que, muitas vezes, são ocupadas por pessoas sem qualquer tipo de deficiência, conforme expressam os seguintes relatos:

Tem pouca vaga também para deficiente... muito pouca. É muito difícil você achar uma vaga para deficiente que esteja ocupada realmente por um deficiente. [M3] 
Às vezes ainda não consegue, né? porque tem muita gente que é normal e pega vaga de quem precisa, né?" [M15] A população é meio complicada de lidar. Tem dia que você chega no estacionamento de vaga de cadeirante e tá estacionado o carro comum e eles acham que tá no lugar certo. [M17]

Segundo as participantes, as rampas de acesso ainda não estão disponíveis por toda a cidade e, quando se encontram acessíveis, as calçadas estão cheias de buracos ou possuem configurações que dificultam a locomoção. Segundo algumas entrevistadas:

Os passeios estão muito difícil.... A rampinha e o passeio são cheio de buracos e as rodas das cadeiras vai caindo e furando. E às vezes faz aquele passeio de pedrinha preta, aquelas que são um pouquinho maior, você custa andar. [M17]

Essas rampinhas nas calçadas, não é todo lugar que você encontra e quando tem é só a rampa né? Porque a calçada inteira tá toda esburacada... então tem que andar na rua. [M10]

\section{DISCUSSÃO}

Um estudo com crianças portadoras de paralisia cerebral e seus cuidadores, igualmente ao presente estudo, as crianças apresentaram importantes alterações do nível motor, além disso, verificou-se que os cuidadores são os próprios familiares, principalmente as mães, de modo que a tarefa de cuidar faz com que os familiares sofram um contínuo processo de adaptação física, emocional e social11.

As entrevistas realizadas com os participantes do presente estudo evidenciaram que as famílias enfrentam diferentes contratempos, como atitude não inclusiva dos demais cidadãos, pouco investimento em acessibilidade nas regiões periféricas da cidade, e existência de barreiras que dificultam a locomoção dos deficientes. A falta de acessibilidade intensifica profundamente as exigências para as famílias das crianças com deficiência ${ }^{11}$.

Com a Lei nำ10.098, empresas públicas e concessionárias de transporte coletivo passaram a possuir um lugar reservado e identificado para os indivíduos com deficiência, idosos, gestantes e pessoas com crianças no colo. Ademais, os veículos produzidos um ano após a promulgação da lei devem ser planejados para o fácil acesso das pessoas a seu interior ${ }^{7}$.

0 transporte coletivo possibilita que os indivíduos acessem inúmeros locais, como lojas, o domicílio, o trabalho e lazer, garantindo assim um direito de "ir e vir" estabelecido pela constituição brasileira12. A utilização desses transportes por pessoas com deficiências ou mobilidade reduzida pode ser um grande desafio, já que o desenho do automóvel é composto por degraus altos, disposição desfavorável do corrimão, assentos e catracas ${ }^{13}$.

Com o propósito de reduzir as barreiras nos meios de transporte públicos, podem-se adotar tecnologias alternativas, como os pisos baixos que possibilitam o acesso ao interior do ônibus no mesmo nível da calçada ou de qualquer outro ponto de parada ${ }^{13}$. A ABNT, por meio da NBR 14022/06, institui parâmetros e critérios técnicos de acessibilidade ao transporte coletivo de acordo com as indicações do desenho universal, a fim de garantir a acessibilidade de forma segura e autônoma ${ }^{12}$.

Em pesquisa realizada com deficientes, usuários de transporte coletivo da cidade de Uberaba-MG, foram encontrados relatos semelhantes aos das mães do presente estudo. Os depoimentos dos utilizadores de ônibus mostraram que a acessibilidade adequada ao ônibus depende de variáveis como a conservação de equipamentos e habilidade técnica dos condutores e cobradores. Sabe-se que apenas as leis relacionadas a equipamentos e mobiliários não são suficientes para garantir um transporte acessível, sendo também necessário o treinamento contínuo e a preparação de motoristas e cobradores ${ }^{12}$.

Uma pesquisa desenvolvida em 2010 na cidade de Manaus-AM com usuários de cadeiras de rodas mostrou que $80 \%$ dos participantes utilizam transporte público. Os entrevistados denunciaram o descaso da população, que frequentemente ocupa o espaço dos cadeirantes e age com indiferença em relação a eles; além disso, a falta de treinamento para a elevação dos deficientes físicos ao ônibus pode fazer com que a atividade demore em média 30 minutos ${ }^{14}$.

As barreiras urbanísticas são aquelas que dificultam o acesso ou locomoção dos deficientes ou com mobilidade reduzida aos espaços. Essas barreiras existem em lugares 
públicos e privados e impedem o exercício da cidadania, em sua plenitude, devido à dificuldade de deslocamento. São exemplos de barreiras urbanísticas: escadas, calçadas com degraus, rampas com inclinações exageradas, portas estreitas, entre outros.

No que diz respeito às vagas especiais para pessoas com deficiência, o artigo 7 da Lei no10.098 garante que, em todos os estacionamentos de veículos e em vias ou espaços públicos, existam vagas reservadas e sinalizadas. Tais vagas devem ser localizadas próximas aos acessos de circulação de pedestre e devem estar presentes em número equivalente a $2 \%$ do total de vagas ${ }^{7}$.

Um estudo investigou as instalações físicas dos hospitais públicos de João Pessoa-PB, buscando verificar a acessibilidade para deficientes e indivíduos com mobilidade reduzida e verificou-se que apenas um dos hospitais apresentava uma vaga reservada e sinalizada com o Símbolo Internacional de Acesso (SIA) ${ }^{15}$. Em outro estudo, realizado em João Pessoa, constatou-se que 97,8\% das Unidades de Saúde da Família não possuíam estacionamento para pessoas com deficiência ${ }^{16}$. Tais resultados corroboram com as exposições deste estudo, uma vez que as mães relatam a existência de poucas vagas.

Ainda em relação às vagas para deficientes, uma pesquisa realizada com 29 agências bancárias identificou que 20 não possuíam vagas destinadas aos deficientes. Desse modo, em 10 agências públicas, apenas cinco possuíam vagas especiais, e das 19 agências privadas, apenas quatro disponibilizaram vagas para deficientes ${ }^{17}$. Outra investigação, realizada em bibliotecas de Portugal, apurou que metade das 25 bibliotecas estudadas não possuíam estacionamento próprio nas redondezas e nem sinalização para as pessoas com deficiência ou mobilidade reduzida ${ }^{18}$.

No tocante às calçadas, a NBR 9050 determina que essas devem permanecer desobstruídas e isentas de interposições, como buracos, desnivelamentos e obstáculos que impeçam ou dificultem a locomoção das pessoas. No que diz respeito às rampas, a inclinação deve estar de acordo com os limites estabelecidos pela NBR 9050, e a largura deve ser estabelecida de acordo com o fluxo de pessoas; além disso, as escadas fixas e degraus devem estar associados à rampa ou ao equipamento de transporte vertical. Ademais, é importante lembrar que, junto à vaga de estacionamento, deve haver rebaixamento total do passeio que coincida com a projeção da abertura de porta dos veículos ${ }^{19}$.

Em uma investigação efetuada em 157 Unidades de Atenção Primária à Saúde (UAPS), situadas em 16 municípios da região do Maciço de Baturité, localizada no Estado do Ceará, observou-se que 39\% das escadas e $74 \%$ das rampas de acesso encontravam-se inacessíveis aos deficientes ${ }^{20}$. Para que a acessibilidade e a inclusão ocorram de forma efetiva, é de extrema importância que as unidades de saúde ofereçam acesso físico e adaptações ambientais apropriada as pessoas com deficiências ${ }^{21}$.

Outra investigação revelou que 63,9\% dos usuários do sistema público de saúde com deficiência ou restrição de mobilidade deparam-se com barreiras do tipo em rampas e calçadas no caminho que percorrem de suas residências ao local de atendimento ${ }^{22}$. Esses achados vão ao encontro dos relatos expostos no presente estudo.

Outra pesquisa com quatro hospitais públicos verificou que as calçadas possuíam obstáculos como entulhos e buracos. Também foi possível observar que apenas duas calçadas possuíam rebaixamento de meio-fio em pontos estratégicos ${ }^{15}$.

\section{CONCLUSÃO}

As adaptações urbanas e nos transportes, apesar de presentes, apresentam imperfeições ou não funcionam adequadamente. É sabido que as adaptações precisam estar de acordo com as normas, pois só assim as pessoas com deficiência ou dificuldade de locomoção poderão utilizá-las com segurança.

Dessa forma, é preciso que a manutenção dos transportes coletivos seja feita regularmente para que os equipamentos de adaptação funcionem adequadamente. Também é 
necessário que motoristas e cobradores sejam instruídos sobre como operar os elevadores, e a população deve ser conscientizada sobre a importância da conservação dos dispositivos de adaptação.

A conscientização da população também é de extrema relevância, juntamente com uma fiscalização rigorosa, com vistas a educar os cidadãos sobre a importância das adaptações e conservação dos equipamentos de acessibilidade para aqueles que possuem dificuldade de locomoção.

As inadequações de acessibilidade não só desrespeitam as leis, como dificultam a locomoção dos deficientes e indivíduos com mobilidade reduzida, prejudicando a inclusão e aumentando a demanda e preocupação dos familiares. Visto isso, é importante que os poderes públicos participem mais ativamente das questões referentes à acessibilidade fazendo com que, de fato, a lei seja cumprida.

As limitações do estudo se relacionam ao fato de ser desenvolvido em uma única cidade e com tamanho amostral reduzido, impedindo generalizações, de modo que se sugere estudos similares com tamanhos amostrais mais ampliados e em vários locais diferentes. Por outro lado, esta pesquisa aponta um contexto possivelmente similar a outras realidades e pode, no caso da cidade estudada, apontar pistas para se rever os espaços e a acessibilidade.

\section{REFERÊNCIAS}

1. Araújo AF, Souza MIA, Carrijo DCM, Paschoarel LC. Acessibilidade e ergonomia na inclusão de crianças com deficiência física - análise das EMEFs do município de Guariba (SP). Ação Ergon. [Internet]. 2015 [citado em 05 mar 2019]; 10(1):31-46. Disponível em: http://www.abergo.org.br/revista/index.php/ae/article/view/472

2. Buscaglia L. Os deficientes e seus pais. 5ed. Rio de Janeiro: Record; 2006. 416p.

3. Souza DPM. Acessibilidade aos portadores de deficiência física: uma garantia constitucional. Jus Navigandi [Internet]. 2017 [citado em 05 mar 2019]; 22(5144). Disponível em: https://jus.com.br/artigos/59060

4. Duarte CRS, Cohen R. Proposta de metodologia de avaliação da acessibilidade aos espaços de ensino fundamental. In: Anais NUTAU 2006: Demandas Sociais, Inovações Tecnológicas e a Cidade; 2006; São Paulo. São Paulo: USP; 2006. 12p.

5. Seabra Filho SS. Terminais de integração para transporte público humanizado: estudo ergonômico nos terminais do Grande Recife [dissertação]. Recife: Universidade Federal de Pernambuco; 2015. 200p.

6. Evangelo LS. Avaliação da acessibilidade e mobilidade arquitetônica em escolas de ensino fundamental de Viçosa - MG [dissertação]. Viçosa, MG: Universidade Federal de Viçosa; 2014. $174 \mathrm{p}$.

7. Presidência da República (Brasil). Lei n‥ 10098, de dezembro de 2000. Estabelece normas gerais e critérios básicos para a promoção da acessibilidade das pessoas portadoras de deficiência ou com mobilidade reduzida, e dá outras providências. Diário Oficial da União, Brasília, DF, 20 dez 2000. Seção 1, p. 2.

8. Vieira NGB, Mendes NC, Frota LMCP, Frota MA. O cotidiano de mães com crianças portadoras de paralisia cerebral. Rev Bras Promoç Saúde [Internet] 2008 [citado em 05 mar. 2019]; 21(1):55-60. DOI: 10.5020/18061230.2008.p55

9. Minayo MCS. O desafio do conhecimento: pesquisa qualitativa em saúde. 14ed. São Paulo: Hucitec; 2014. 407p.

10. Gomes R. Pesquisa qualitativa em saúde [monografia]. São Paulo: Instituto Sírio-Libanês de Ensino e Pesquisa; 2014. 45p.

11. Demitto MO, Furlan MCR, Mai LD, Marcon SS. Percepção do cuidador domiciliar de pessoas com paralisia cerebral sobre barreiras arquitetônicas e acessibilidade. Cienc Cuid Saúde [Internet] 2010 [citado em 05 mar 2019]; 9(4):651-9. DOI: 10.4025/cienccuidsaude.v9i4.13811 
12. Vieira AFR, Cavalcanti A, Alves AL. O direito de ir e vir: a acessibilidade do transporte público. Cad Ter Ocup UFSCar [Internet]. 2015 [citado em 05 mar 2019]; 23(4):775-80. DOI: https://doi.org/10.4322/0104-4931.ctoA0505A

13. Rabelo GB. Avaliação da acessibilidade de pessoas com deficiência física no transporte coletivo urbano [dissertação]. Uberlândia, MG: Universidade Federal de Uberlândia; 2008. $117 \mathrm{p}$.

14. Santos ES. Ergonomia e acessibilidade: um estudo de caso sobre os problemas potenciais na concepção de sistema de locomoção para atividades diárias na cidade de Manaus. Projetica [Internet]. 2013 [citado em 05 mar 2019]; 4(1):121-36. DOI: http://dx.doi.org/10.5433/22362207.2013v4n1p121

15. Azevedo TR, Valdevino SC, Costa KNFM, Valdevino Neto J, Lira LGRSH, Martins KP. Accesibilidad para personas con discapacidad física en los hospitales públicos. Enferm Glob. [Internet]. 2015 [citado em 05 mar 2019]; 14(37):310-27. Disponível em: http://scielo.isciii.es/pdf/eg/v14n37/administracion3.pdf

16. Martins KP. Acessibilidade de pessoas com deficiência física e sensorial em unidades de saúde da família [dissertação]. João Pessoa: Universidade Federal da Paraíba; 2015. 75p.

17. Mazetto MF, Cavalcanti A, Dutra FCMS. Vagas de estacionamento para pessoas com deficiência em agências bancárias. Cad Ter Ocup UFSCar [Internet]. 2015 [citado em 05 mar 2019]; 23(2): 313-20. DOI: https://doi.org/10.4322/0104-4931.ctoA00505

18. Nunes MB, Guimarães A. De que falamos quando falamos de inclusão? $O$ acesso às bibliotecas públicas por pessoas portadoras de deficiência [Internet]. In: Actas Congresso Nacional de Bibliotecários, Arquivistas e Documentalistas, 13o Congresso Nacional BAD: Sustentabilidade \& Transformação; 2018; Fundão, Portugal. Lisboa: BAD; 2018 [citado em 05 mar 2019]. 5p. 2 Disponível em: https://www.bad.pt/publicacoes/index.php/congressosbad/article/view/1872/pdf

19. Associação Brasileira de Normas Técnicas. NBR 9050: Acessibilidade a edificações, mobiliário, espaços e equipamentos urbanos. Rio de Janeiro: ABNT; 2004.

20. Marques JF, Áfio ACE, Carvalho LV, Leite SS, Almeida PC, Pagliuca LMF. Physical accessibility in primary healthcare: a step towards the embracement. Rev Gaúcha Enferm. [Internet]. 2018 [citado em 05 mar 2019]; 39:e2017-0009. DOI: https://doi.org/10.1590/19831447.2018.2017-0009

21. Ministério da Saúde (Br), Secretaria de Atenção à Saúde, Departamento de Ações Programáticas Estratégicas. A pessoa com deficiência e o Sistema Único de Saúde. Brasília, DF: Ministério da Saúde; 2008.

22. Amaral FLJS, Holanda CMA, Quirino MAB, Nascimento JPS, Neves RF, Ribeiro KSQS, et al. Acessibilidade de pessoas com deficiência ou restrição permanente de mobilidade ao SUS. Ciênc Saúde Colet. [Internet]. 2012 [citado em 05 mar 2019]; 17(7):1833-40. DOI: http://dx.doi.org/10.1590/S1413-81232012000700022 


\section{CONTRIBUIÇõES}

Adriana Santos Camargos contribuiu na análise dos dados e na redação. Gisélia Gonçalves de Castro participou no planejamento, concepção e obtenção dos dados. Marilurdes Silva Farias atuou na redação e revisão.

\section{Como citar este artigo (Vancouver)}

Castro, GG, Camargos AS, Farias MS. Barreiras de acessibilidade urbana: cotidiano das famílias de crianças com deficiências neurológicas. REFACS [Internet]. 2020 [citado em inserir dia, mês e ano de acesso]; 8(Supl. 2):694-701. Disponível em: inserir link de acesso. DOI: inserir link do DOI.

\section{Como citar este artigo (ABNT)}

CASTRO, G. G.; CAMARGOS, A. S.; FARIAS, M. S. Barreiras de acessibilidade urbana: cotidiano das famílias de crianças com deficiências neurológicas. REFACS, Uberaba, MG, v. 8, p. 694701, 2020. Supl. 2. Disponível em: inserir link de acesso. Acesso em: inserir dia, mês e ano de acesso. DOI: inserir link do DOI.

\section{Como citar este artigo (APA)}

Castro, G.G., Camargos, A.S., \& Farias, M.S. (2020). Barreiras de acessibilidade urbana: cotidiano das famílias de crianças com deficiências neurológicas. REFACS, 8(Supl. 2), 694701. Recuperado em inserir dia, mês e ano de acesso de inserir link de acesso. DOI: inserir link do DOI. 